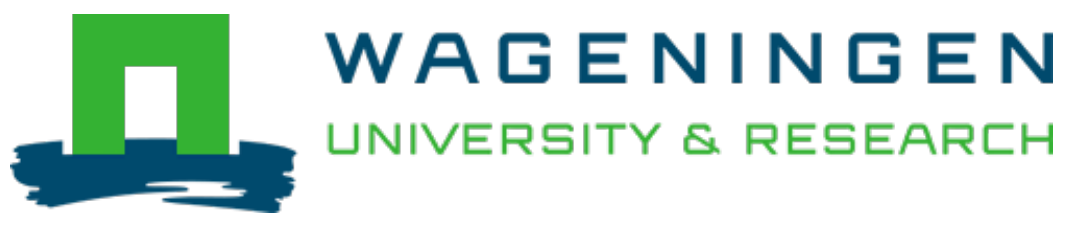

\title{
Anaerobic biodegradation of pharmaceutical compounds coupled to dissimilatory manganese (IV) or iron (III) reduction
}

\author{
Journal of Hazardous Materials \\ Liu, Wenbo; Sutton, Nora B.; Rijnaarts, Huub H.M.; Langenhoff, Alette A.M. \\ https://doi.org/10.1016/j.jhazmat.2018.04.078
}

This article is made publicly available in the institutional repository of Wageningen University and Research, under the terms of article $25 \mathrm{fa}$ of the Dutch Copyright Act, also known as the Amendment Taverne. This has been done with explicit consent by the author.

Article 25 fa states that the author of a short scientific work funded either wholly or partially by Dutch public funds is entitled to make that work publicly available for no consideration following a reasonable period of time after the work was first published, provided that clear reference is made to the source of the first publication of the work.

This publication is distributed under The Association of Universities in the Netherlands (VSNU) 'Article $25 \mathrm{fa}$ implementation' project. In this project research outputs of researchers employed by Dutch Universities that comply with the legal requirements of Article $25 \mathrm{fa}$ of the Dutch Copyright Act are distributed online and free of cost or other barriers in institutional repositories. Research outputs are distributed six months after their first online publication in the original published version and with proper attribution to the source of the original publication.

You are permitted to download and use the publication for personal purposes. All rights remain with the author(s) and / or copyright owner(s) of this work. Any use of the publication or parts of it other than authorised under article $25 \mathrm{fa}$ of the Dutch Copyright act is prohibited. Wageningen University \& Research and the author(s) of this publication shall not be held responsible or liable for any damages resulting from your (re)use of this publication.

For questions regarding the public availability of this article please contact openscience.library@wur.nl 


\title{
Anaerobic biodegradation of pharmaceutical compounds coupled to dissimilatory manganese (IV) or iron (III) reduction
}

\author{
Wenbo Liu ${ }^{1}$, Nora B. Sutton ${ }^{1}$, Huub H.M. Rijnaarts ${ }^{1}$, Alette A.M. Langenhoff \\ Sub-department of Environmental Technology, Wageningen University \& Research, 6708WG, Wageningen, The Netherlands
}

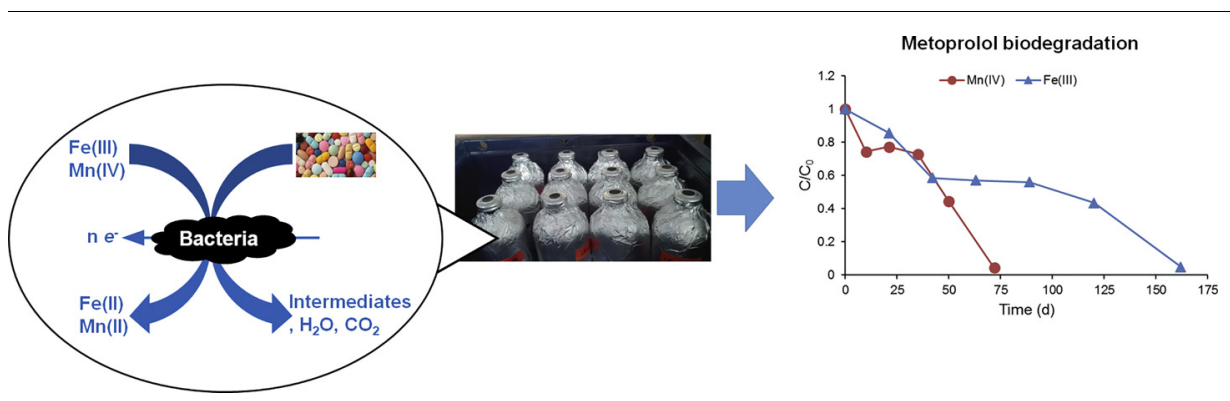

\section{A R T I C L E I N F O}

\section{Keywords:}

Anaerobic conditions

Biodegradation

$\mathrm{Mn}(\mathrm{IV})$ or Fe(III) reduction

Pharmaceuticals

\begin{abstract}
A B S T R A C T
Pharmaceuticals in water have adverse effects on aquatic environment. Anaerobic pharmaceutical biodegradation coupled to dissimilatory manganese(Mn) (IV)- or iron(Fe) (III)-oxides reduction is potentially efficient but unexplored. In this study, batch experiments were performed using different Mn(IV) and Fe(III) species with a microbial inoculum pre-cultivated with $15 \mathrm{mM}$ chemically-synthesized $\mathrm{Mn}$ (IV) and $10 \mathrm{mg} \mathrm{L}^{-1}$ metoprolol. Results show 26\% caffeine and 52\% naproxen are degraded with Mn(IV) as terminal electron acceptor and insignificant biodegradation for other pharmaceuticals tested. Reduction of Mn(IV) from drinking water treatment is coupled to anaerobic biodegradation of metoprolol and propranolol, resulting in removal efficiencies of $96 \%$ and $31 \%$, respectively. The results indicate that adsorption contributes to the pharmaceutical removal during the first 10 days of incubation, while biodegradation is the main removal mechanism in the whole period. $\mathrm{Fe}(\mathrm{III})$ can also be used as electron acceptor in anaerobic pharmaceutical biodegradation. Over half of the added metoprolol is degraded with both chemically-synthesized Fe(III) and Fe(III)-citrate as terminal electron acceptors. However, this process did not occur when using Fe(III) from drinking water treatment or Fe(III)-based sorbents. This study indicates that anaerobic pharmaceutical biodegradation coupled to dissimilatory Mn(IV) or $\mathrm{Fe}(\mathrm{III})$ reduction is possible, and promising for application to cleaning wastewater treatment plant effluents.
\end{abstract}

\section{Introduction}

In the last decades, there is concern about pharmaceutical chemicals in water due to the increased consumption of these compounds and improvements in the detection of these compounds. These chemicals are observed in surface water, groundwater, wastewater, and even in

\footnotetext{
*Corresponding author at: Sub-department of Environmental Technology, Wageningen University and Research, P.O. Box 17, 6700 AA Wageningen, The Netherlands.

E-mail addresses: wesssnbo.liu@wur.nl (W. Liu), nora.sutton@wur.nl (N.B. Sutton), huub.rijnaarts@wur.nl (H.H.M. Rijnaarts), alette.langenhoff@wur.nl (A.A.M. Langenhoff).

${ }^{1}$ Sub-department of Environmental Technology, Wageningen University and Research, P.O. Box 17, 6700 AA Wageningen, The Netherlands.
} 
drinking water in the range from $\mathrm{ng} \mathrm{L}^{-1}$ to $\mu \mathrm{gL}^{-1}$ [1,2]. Previous studies have shown that pharmaceuticals have adverse effects. For example, after 4 week of exposure to propranolol at concentrations as low as $0.5 \mu \mathrm{g} \mathrm{L}^{-1}$, a decrease in the reproduction of fish (Oryias latipes) has been observed [3]. Consequently, pharmaceuticals as emerging contaminants are unwanted even at low level concentrations, and compounds like diclofenac or clarithromycin have been classified as a priority substances in water quality watch lists $[4,5]$.

Conventional wastewater treatment facilities insufficiently remove pharmaceuticals such as diclofenac, carbamazepine, and $\beta$-blockers. The removal efficiency is generally less than 50\% [6]. To eliminate these pharmaceuticals from water, technologies such as advanced oxidation processes, activated carbon adsorption, and membrane filtration are applied. For example, complete removal of the pharmaceuticals propranolsssol and diclofenac as well as 75\% carbamazepine removal can be achieved in catalytic photodegradation $[7,8]$. However, some intermediates from these advanced technologies can be more toxic than their parent compounds, which is undesired [9]. Furthermore, the high energy consumption will increase the ecological footprint and potential cost, making these technologies less attractive [10].

Biodegradation can be a less energy consuming way to efficiently remove pharmaceuticals and different redox conditions can be applied [10-12]. Under aerobic conditions, biodegradation of ibuprofen and diclofenac can achieve $75-100 \%$ removal [10]. Under nitrate-reducing conditions, biodegradation is efficient for $\beta$-blockers like atenolol and propranolol [13]. Under sulphate-reducing conditions, over $50 \%$ atenolol can be biodegraded within one week [14]. Under methanogenic conditions, more than $80 \%$ of diclofenac, ibuprofen, naproxen, and ketoprofen were found to be biodegraded [15]. However, alternative electron acceptors such as Mn(IV) or Fe(III) are less studied compared to the other redox conditions.

Applying Mn(IV) or Fe(III) as electron acceptors in anaerobic biodegradation of pollutants has clear advantages. In comparison to other electron acceptors like nitrate or sulphate, adding solid Mn(IV) and Fe (III) could avoid increasing wastewater salinity, and it is easy in application. The reduced products, Mn(II) and Fe(II), can be easily reoxidized via a biological low-energy process. In addition, using Mn(IV) or Fe(III) could also remove other pollutants like ammonia or heavy metals simultaneously [16,17].

Anaerobic biodegradation under Mn(IV)- or Fe(III)-reducing conditions is also known as dissimilatory $\mathrm{Mn}$ (IV) or Fe(III) reduction. During the process, Mn(IV)- or Fe(III)- (hydr)oxides are used as terminal electron acceptors in the anaerobic biodegradation of organic compounds [17]. Previous studies show that anaerobic biodegradation with $\mathrm{Mn}(\mathrm{IV})$ as terminal electron acceptor can efficiently remove aromatic compounds such as benzene, toluene, and polyaromatics: for example, naphthalene is mineralized to $\mathrm{CO}_{2}$ and water for more than $60 \%$ [18]. To date, anaerobic degradation of naproxen and atenolol under Mn(IV)- or Fe(III)-reducing conditions is described [13,14]. These results indicate that anaerobic biodegradation coupled to dissimilatory $\mathrm{Mn}(\mathrm{IV})$ or $\mathrm{Fe}(\mathrm{III})$ reduction can be effective to remove pharmaceuticals as a wastewater treatment technology. During this anaerobic pharmaceutical biodegradation, $\mathrm{Mn}(\mathrm{IV})$ and $\mathrm{Fe}(\mathrm{III})$ are consumed as terminal electron acceptor.

In addition to pharmaceutical removal efficiency, the influence of $\mathrm{Mn}(\mathrm{IV})$ or Fe(III) from different sources are important for application. Chemically synthesized Mn(IV) or Fe(III) (labeled as Mn(IV) chem-synthesis $_{\text {s. }}$ and $\mathrm{Fe}(\mathrm{III})_{\text {chem-synthesis }}$ ) as well as the $\mathrm{Mn}$ (IV) or $\mathrm{Fe}(\mathrm{III})$ from natural source are commonly used, and reported in literature [17,18]. Compared to these compounds, $\mathrm{Mn}(\mathrm{IV})$ or Fe(III) produced during the drinking water treatment (labelled as Mn(IV) $)_{\text {DWTP }}$ and Fe(III) $)_{\text {DWTP }}$ ) could be a more desirable source. Mn(IV) $)_{\text {DWTP }}$ and Fe(III) $)_{\text {DWTP }}$ are waste streams from the drinking water treatment plants [19]. Thus, these materials could be a cheap alternative for $\mathrm{Mn}(\mathrm{IV})_{\text {chem-synthesis }}$ and $\mathrm{Fe}$ (III) $)_{\text {chem-synthesis. For example, Fe(III) }}$ DWTP usually consist of $\mathrm{FeOOH}$, which is a suitable electron acceptor in anaerobic biodegradation processes $[17,20]$. In addition, different types of Mn(IV) or Fe(III) can serve as electron acceptor during anaerobic biodegradation of organic compounds [17]. To the best of our knowledge, there are no studies reported directly using $\mathrm{Mn}(\mathrm{IV})_{\text {DWTP }}$ or $\mathrm{Fe}(\mathrm{III})_{\text {DWTP }}$ in dissimilatory metal reduction, nor using it coupled to the removal of pharmaceuticals with these Mn(IV) or Fe(III) species as terminal electron acceptor.

In this study, we tested the anaerobic biodegradation of pharmaceuticals with different types of Mn(IV) or Fe(III). Since anaerobic biodegradation of aromatic compounds with $\mathrm{Mn}(\mathrm{IV})$ or Fe(III) as electron acceptor has been observed, the process is also expected to be effective in removal of aromatic pharmaceuticals. The results presented provide information on anaerobic pharmaceutical biodegradation coupled to dissimilatory $\mathrm{Mn}$ (IV) or Fe(III) reduction and that contributes to understanding the fate and transfer of pharmaceuticals in the environment, where $\mathrm{Mn}$ (IV) or Fe(III) are ubiquitous, and which opens new ways towards application in waste water treatment.

\section{Methods and materials}

\subsection{Chemicals}

Anaerobic water was prepared as previously described by boiling either ultrapure water $(18.2 \mathrm{M} \Omega \cdot \mathrm{cm}$, Total Organic Carbon $(\mathrm{TOC})=18 \mathrm{ppb}$, Millipore, USA) or demineralized water (demiwater) for $5 \mathrm{~min}$, followed by cooling down to room temperature under a gentle $\mathrm{N}_{2}$ flow [21]. The anaerobic water was stored in closed glass bottles at room temperature. All the solutions in this study were prepared with anaerobic water unless specified.

Six pharmaceuticals were purchased from Sigma-Aldrich or MP Biomedicals including caffeine, carbamazepine, ibuprofen, metoprolol, naproxen, and propranolol. The chemical structure and properties of these compounds have been described previously [21]. A stock solution of the pharmaceutical mixture was prepared with anaerobic ultrapure water, at a concentration of $20 \mathrm{mg} \mathrm{L}^{-1}$ for each pharmaceutical. Metoprolol stock and propranolol stock were prepared separately with anaerobic ultrapure water at $1 \mathrm{~g} \mathrm{~L}^{-1}$.

Other chemicals were purchased from Sigma-Aldrich. For solid chemicals, the purity was greater than $98 \%$ while the liquids had a purity at HPLC or UPLC quality.

\subsection{Preparation of $\mathrm{Mn}(\mathrm{IV})$ or $\mathrm{Fe}(I I I)$}

Different types of Mn(IV) and Fe(III) were used in this study (Table S1). The Mn(IV) $)_{\text {chem-synthesis }}$ was prepared as described previously [21]. The Mn(IV) DWTP (Fig. S1) originated from drinking water production plant 'Noordbargeres' in Emmen, kindly provided by Water Laboratorium Noord (WLN, the Netherlands) [22].

Soluble Fe(III)-citrate was dissolved with boiled demiwater. After cooling down under $\mathrm{N}_{2}$ flush to room temperature, the $\mathrm{pH}$ of $\mathrm{Fe}(\mathrm{III})-$ citrate was adjusted to $\mathrm{pH} 7$ with $1 \mathrm{~N} \mathrm{NaOH}$ and diluted to $40 \mathrm{mM}$. The $\mathrm{Fe}(\mathrm{III})$-citrate solution was stored in a closed glass bottle and covered with aluminum foil to avoid photodegradation.

$\mathrm{Fe}(\mathrm{III})_{\text {chem-synthesis }}$ was prepared based on the method described previously [18]. In brief, $0.4 \mathrm{M} \mathrm{FeCl}_{3}$ was neutralized with $1 \mathrm{~N} \mathrm{NaOH}$ until $\mathrm{pH}$ 7. Thereafter, $\mathrm{Fe}(\mathrm{III})_{\text {chem-synthesis }}$ was washed and stored as $\mathrm{Mn}$ (IV) $)_{\text {chem-synthesis. }}$ Fe(III) $)_{\text {DWTP }}$ was obtained from Evides Waterbedrijf (the Netherlands). These Fe(III) $)_{\text {DWTP }}$ granules are a mixture of Fe(III) from different drinking water treatment plants and then pelletized. Two types of Fe(III)-based sorbents, FerroSorp ${ }^{\circledR}$ Plus and FerroSorp ${ }^{\circledR}$ RW (la-

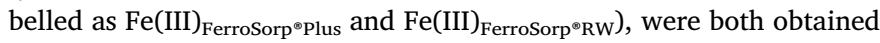
from HeGo Biotec $\mathrm{GmbH}$ in granular form (Germany).

\subsection{Experimental setup}

(1) Inoculum

Inoculum used in the experiments with $\mathrm{Mn}(\mathrm{IV}), \mathrm{Fe}(\mathrm{III})_{\text {chem-synthesis }}$ 
and Fe(III)-citrate consisted of a mixture of anaerobic sediments in the effluent channel of wastewater treatment plants in the Netherlands (Text S1). This sediment mixture has been incubated in the presence of $10 \mathrm{mg} \mathrm{L}^{-1}$ metoprolol and $\left.15 \mathrm{mM} \mathrm{Mn(IV)}\right)_{\text {chem-synthesis }}$ for over 800 days in cultivation medium described previously (Table S2) [23]. In the experiments with $\mathrm{Fe}(\mathrm{III})_{\text {chem-synthesis, }}$, the mixture samples were taken out after 100-day incubation. These samples were used as a new in-

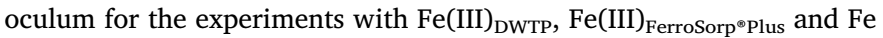

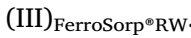

(2) Experimental preparation

All experiments were performed in the same medium, as previously described [23]. The medium was prepared under anaerobic conditions in an anaerobic glovebox. In the experiment with Mn(IV), $0.02 \%$ yeast extract was added to the medium, in order to provide sufficient nutrient compounds but in the experiments with Fe(III), no yeast extract is in the medium.

The experiments with Mn(IV) $)_{\text {chem-synthesis }}$ were carried out in duplicate in $250 \mathrm{~mL}$ bottles, filled with $100 \mathrm{~mL}$ anaerobic medium. The experimental bottles were prepared in the anaerobic glovebox. A selected amount of $\mathrm{Mn}(\mathrm{IV})_{\text {chem-synthesis }}$ was distributed to the bottles, achieving a final concentration of $15 \mathrm{mM} \mathrm{Mn}(\mathrm{IV}) .10 \mathrm{~mL}$ inoculum mixture was transferred to the experimental bottles. Since the experiments were carried out as a primary study for proof-of-principle, a relatively high pharmaceutical concentration was used. In the experiments, the stock solution of pharmaceutical mixture was added to reach a final concentration of $10 \mathrm{mg} \mathrm{L}^{-1}$ for each pharmaceutical.

The experiments with Mn(IV) $)_{\text {DWTP }}$ (granule and ground powder) were performed in duplicate in $120 \mathrm{~mL}$ bottles, filled with $50 \mathrm{~mL}$ medium inside an anaerobic glovebox. About $4 \mathrm{~g}$ dry $\mathrm{Mn}(\mathrm{IV})_{\mathrm{DWTP}}$ was added into the bottles, resulting in a final concentration of $15 \mathrm{Mm} \mathrm{Mn}$ (IV). Only metoprolol and propranolol were tested to minimalize the potential influence of pharmaceuticals on inoculum. $0.5 \mathrm{~mL}$ metoprolol stock solution and $0.5 \mathrm{~mL}$ propranolol stock solution were added to the bottles. The final concentration for each pharmaceutical was $10 \mathrm{mg} \mathrm{L}^{-1} .5 \mathrm{~mL}$ inoculum mixture was transferred to the experimental bottles.

$\mathrm{Fe}(\mathrm{III})$ is hypothesised as an alternative electron acceptor of Mn(IV) in anaerobic pharmaceutical biodegradation. The experiments with $\mathrm{Fe}$ (III) $)_{\text {chem-synthesis }}$ were repeating the adaption of the inoculum but in the process, $40 \mathrm{mM} \mathrm{Fe}(\mathrm{III})_{\text {chem-synthesis }}$ was used instead of $15 \mathrm{mM} \mathrm{Mn}$ (IV) $)_{\text {chem-synthesis. }}$ The experiments with Fe(III)-citrate were also the same but the $40 \mathrm{mM} \mathrm{Fe}(\mathrm{III})$-citrate solution replaced the anaerobic water during the medium preparation. Only $1 \mathrm{~mL}$ metoprolol stock solution was added to reach a final concentration of $10 \mathrm{mg} \mathrm{L}^{-1}$.

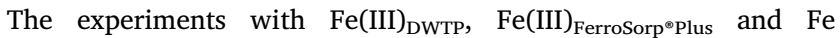

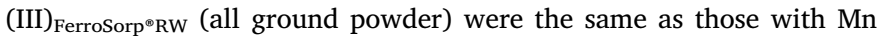
(IV) $)_{\text {DWTP }}$ in a $120 \mathrm{~mL}$ bottles in duplicate. The final concentration of Fe (III) in these experiments was $40 \mathrm{mM}$. Only metoprolol was added into the experiments at a final concentration of $10 \mathrm{mg} \mathrm{L}^{-1}$.

When the bottles were ready, all the bottles were closed with butylrubber stoppers and taken out of the glovebox. The bottles were sealed with aluminum crimp caps, and the headspace was exchanged to $\mathrm{N}_{2}$ / $\mathrm{CO}_{2}(80 \% / 20 \%)$. All experiments were conducted at $30^{\circ} \mathrm{C}$ in the dark without shaking. Abiotic controls were prepared similarly, with additional aliquots of $\mathrm{HgCl}_{2}\left(0.1 \mathrm{gHg} \mathrm{L}^{-1}\right)$ and $\mathrm{NaN}_{3}(0.3 \mathrm{mM})$ to inhibit biotic activity.

\subsection{Sample preparation and analysis}

Liquid samples for pharmaceutical analysis were taken every 3 weeks. After sampling, the samples were centrifuged for $10 \mathrm{~min}$ at $10,000 \mathrm{rpm}$. The supernatant was diluted and transferred to amber vials. All the samples were stored at $-20^{\circ} \mathrm{C}$ before analysis. The overall recovery rate of the sample preparation is $>98 \%$ as previously described [24]. Pharmaceutical analysis was performed by an ultra-performance liquid chromatography with a diode array detector (UPLC, ultimate 3000, Thermo, USA), as previously described [7]. The detection limit of UPLC was $50 \mu \mathrm{g} \mathrm{L}{ }^{-1}$.

The samples for $\mathrm{pH}$ were taken at the beginning and at the end of the experiments, and were analysed immediately with a pH-meter (MeterLab PHM210, Radiometer Analytical).

The samples for morphologies of the Mn(IV) and Fe(III) were prepared by grinding if the raw materials were granular. The morphology was analysed by an X-ray powder diffraction (XRD, Bruker D8 advance).

Samples for Mn content in Mn(IV) DWTP $_{\text {were reduced by } 0.5 \mathrm{mM}}$ $\mathrm{NH}_{2} \mathrm{OH} \cdot \mathrm{HCl}$ ( $1 \mathrm{mg}$ sample/mL). The samples for $\mathrm{Mn}(\mathrm{II})$ measurement were also taken at the end of the experiments. The samples were centrifuged at $10,000 \mathrm{rpm}$ for $10 \mathrm{~min}$. The supernatant was collected and stored at $-4{ }^{\circ} \mathrm{C}$ before analysis. The Mn content and Mn(II) were both measured at wavelength $257.610 \mathrm{~nm}$ by an inductively coupled plasma optical emission spectrometry (ICP-OES) equipped with a MPX megapixel detector (VISTA-MPX CCD Simultaneous, VARIAN co.).

Samples for $\mathrm{Fe}$ analysis were prepared by a modified $\mathrm{HCl}$ extraction method [25]. Briefly, $0.5 \mathrm{~mL}$ samples were mixed with $0.5 \mathrm{~mL} 1 \mathrm{M} \mathrm{HCl}$ to fix Fe(II). Thereafter, Fe(II) was analyzed directly by colourmetric methods (Hach Dr. Lange Kit 340). The samples were analysed immediately. The Fe content in Fe(III) DWTP $_{\text {, Fe(III) }}{\text { Ferrosorp }{ }^{\oplus} \text { Plus }}$ and $\mathrm{Fe}$ (III) ${\text { FerroSorp }{ }^{\circledR} \mathrm{RW}}$ was measured by the same ICP-OES at the wavelength $238.204 \mathrm{~nm}$, while the $\mathrm{Fe}(\mathrm{II})$ generated during the experiments was measured using a Hach Dr. Lange Kit (LCK 340).

\section{Results and discussion}

\subsection{X-ray diffraction of $M n(I V)$ and $F e(I I I)$}

First, the Mn(IV) and Fe(III) were characterized by X-ray diffraction (XRD), to identify the morphologies of these compounds and to assess if they are able to be used in dissimilatory Mn(IV) or Fe(III) reduction. The XRD pattern shows that the Mn(IV) chem-synthesis $_{\text {is amorphous with }}$ two small but broad XRD peaks, similar as previously described by others (Fig. 1) [26]. The morphology of Mn(IV) $)_{\text {DWTP }}$ could not be clarified by an XRD analysis. Since $\mathrm{Mn}(\mathrm{IV})_{\mathrm{DWTP}}$ is $\mathrm{MnO}_{2}$-coated sand, the XRD pattern highly matches the pattern of quartz (Fig. 1(a), Fig.

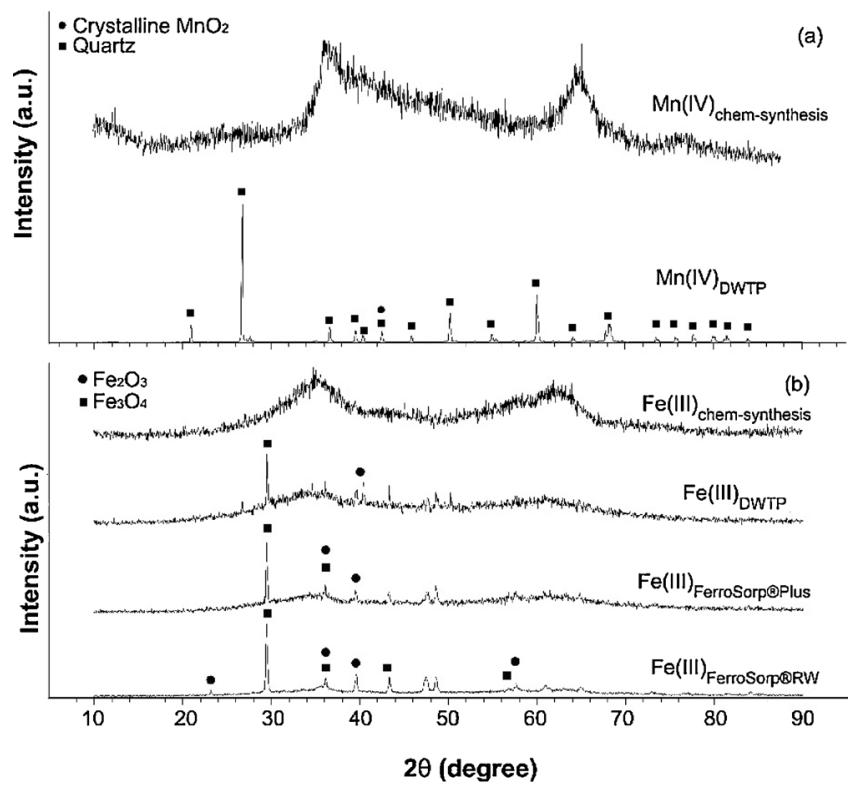

Fig. 1. XRD patterns of different types of (a) chemically synthesised Mn(IV)

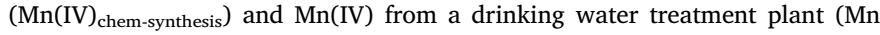

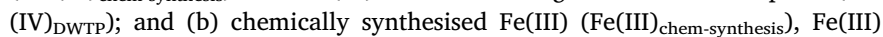
from a drinking water treatment plant (Fe(III) $)_{\text {DWTP }}$ ), and two Fe(III)-based sorbents Fe(III) FerroSorp $^{\star}$ Plus and Fe(III) FerroSorp $^{\circledR}$ RW . 
S2(a)).

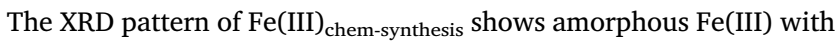
two small but broad XRD peaks, which is a similar pattern as $\mathrm{Fe}(\mathrm{OH})_{3}$ (Fig. 1(b), Fig. S2(b)). The XRD patterns of Fe(III) $)_{\text {DWTP, }}$ Fe (III) FerroSorp $^{\oplus \text { Plus }}$ and Fe(III) Ferrosorp $^{\oplus \mathrm{RW}}$ are all partially similar to those of $\mathrm{Fe}_{2} \mathrm{O}_{3}$ and $\mathrm{Fe}_{3} \mathrm{O}_{4}$, indicating a semi-crystalline morphology. The morphology of $\mathrm{Fe}(\mathrm{III})_{\mathrm{DWTP}}$ is closest to an amorphous one, and $\mathrm{Fe}$ (III) ${\text { Ferrosorp }{ }^{\oplus} \mathrm{RW}}_{\text {is closer to a crystalline morphology. }}$

Based on the literature, the amorphous Mn(IV) and Fe(III) are commonly used Mn and Fe species, and different types of Mn(IV) and Fe (III) such as crystalline hematite, goethite, akaganeite, and magnetite, are suitable for dissimilatory $\mathrm{Mn}(\mathrm{IV})$ or $\mathrm{Fe}(\mathrm{III})$ reduction [17,27]. Therefore, the amorphous and semi-crystalline Mn(IV) and Fe(III) in this study are expected to be able to be used in the dissimilatory Mn(IV) or $\mathrm{Fe}(\mathrm{III})$ reduction.

\subsection{Anaerobic biodegradation of pharmaceuticals with Mn(IV)}

\section{(1) Chemically synthesized Mn(IV)}

Anaerobic biodegradation with Mn(IV) $)_{\text {chem-synthesis }}$ was tested with a mixture of six commonly used pharmaceuticals. Our results show that the anaerobic biodegradation is effective within 40 days (Fig. 2). In this period, $26 \%$ of the applied caffeine, and $52 \%$ of the dosed naproxen is removed. Carbamazepine and propranolol are removed within 42 days at lower levels, namely $12 \%$ and $16 \%$, respectively. No removal is observed for ibuprofen and metoprolol. During the anaerobic biodegradation of pharmaceuticals, $5.4 \mathrm{mM} \mathrm{Mn}(\mathrm{IV}$ ) is reduced (Table 1), indicating that the $\mathrm{Mn}(\mathrm{IV})$ is the electron acceptor in the anaerobic biodegradation. In the abiotic controls, no degradation of pharmaceuticals is observed (Fig. 1), further indicating that the observed degradation is linked to $\mathrm{Mn}(\mathrm{IV})$ reduction.

Based on previous studies, anaerobic biodegradation of pharmaceuticals coupled to dissimilatory Mn(IV) reduction may occur via two pathways [17]. First of all, the pharmaceuticals could be hydrolysed or fermented by different bacteria to easier degradable components, such as sugars, amino acids, long chain fatty acid, and/or simpler aromatic intermediates $[17,28]$. These components can be further converted to fermented acids and hydrogen and then consumed by bacteria. In addition, the pharmaceuticals, as well as the potential aromatic intermediates, can also be oxidised directly by bacteria like Geobacter matallereducens. Mn(IV) reduction in this process provides energy for these bacteria [17].

Since the pharmaceutical removal coupled to dissimilatory Mn(IV)

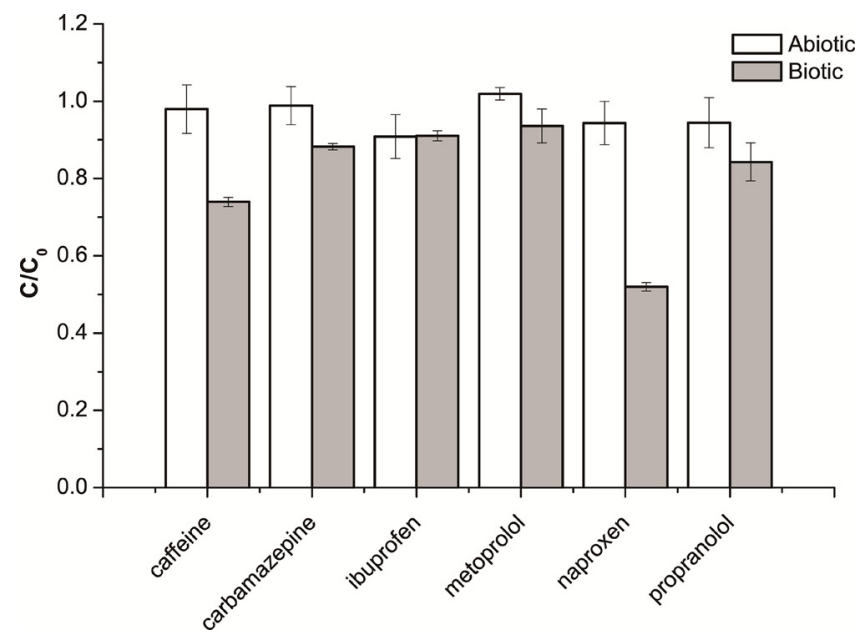

Fig. 2. Biodegradation of pharmaceuticals with chemically synthesized Mn

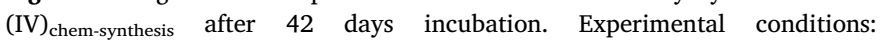
$\left[\mathrm{MnO}_{2}\right]_{0}=15 \mathrm{mM}$, [pharmaceutical $]_{0}=10 \mathrm{mg} \mathrm{L}^{-1}, \mathrm{pH} 6.5-7.5, \mathrm{~T}=30^{\circ} \mathrm{C}$. Error bars stand for the difference between the duplicate experiments.
Table 1

$\mathrm{Mn}(\mathrm{IV})$ or Fe(III) reduction during the anaerobic biodegradation of pharmaceuticals.

\begin{tabular}{lll}
\hline $\begin{array}{l}\text { Mn or Fe used in } \\
\text { experiments }^{\mathrm{a}}\end{array}$ & $\begin{array}{l}\text { Theoretical Mn(IV) or Fe } \\
\text { (III) reduced }(\mathrm{mM})^{\mathrm{b}}\end{array}$ & $\begin{array}{l}\text { Measured Mn(IV) or Fe } \\
(\mathrm{III}) \text { reduced }(\mathrm{mM})^{\mathrm{c}}\end{array}$ \\
\hline Mn(IV) $)_{\text {chem-synthesis }}$ & 1.8 & 5.4 \\
Mn(IV) $)_{\text {DWTP }}$ & 2.2 & 4.9 \\
Fe(III) chem-synthesis $_{\text {Fe(III)-citrate }}$ & 1.7 & 1.8 \\
& 1.2 & 8.8 \\
\hline
\end{tabular}

${ }^{\text {a }} \mathrm{Mn}(\mathrm{IV})_{\text {chem-synthesis }}=$ Chemically produced $\mathrm{Mn}(\mathrm{IV})$ oxides, $\mathrm{Mn}$ $(\mathrm{IV})_{\text {DWTP }}=\mathrm{Mn}(\mathrm{IV})$ oxides from drinking water treatment plants, Fe(III) $)_{\text {chem- }}$ synthesis = Chemically synthesized Fe(III) hydroxides.

$\mathrm{b}$ The calculation methods of Mn(IV) or Fe(IV) reduced described in Text S2 and Table S3.

c Measured Mn(IV) or Fe(IV) reduced is calculated by the difference between the biotic experiments and abiotic controls.

reduction is a biological process, the process is expected to be more effective for readily biodegradable pharmaceuticals. In this study, the removal of naproxen and caffeine is higher than other compounds. Previous studies have shown that naproxen and caffeine are efficiently removed under anaerobic conditions [13,29] while the rest of pharmaceuticals are resistant $[13,30]$. That indicates that naproxen and caffeine could be more biodegradable than other pharmaceuticals. Apparently, removal of naproxen and caffeine is also more effective in anaerobic biodegradation with Mn(IV) ${ }_{\text {chem-synthesis }}$ as shown here.

$\mathrm{Mn}$ (IV) reduced in the experiments is more than two times higher than that in theoretical calculation (Table 1), taking the depleted pharmaceutical amounts as the quantity of consumed electron donor (Text S2, Table S3). The dis-match is most likely due to the presence of yeast extract, which also contains a lot of organic compounds. Therefore, the bacteria will use yeast extract not only as a nutrient source, but also as electron donor to reduce Mn(IV). As a result, more Mn(IV) reduction is observed than calculated for pharmaceutical removal.

Degradation of pharmaceuticals selected in this study under anaerobic conditions has been reported using electron acceptors other than $\mathrm{Mn}(\mathrm{IV})$ or Fe(III). Degradation of caffeine, naproxen, and ibuprofen was observed previously under anaerobic conditions. High removal of caffeine and naproxen, both over $90 \%$, has been obtained under nitratereducing, sulphate-reducing, and methanogenic conditions $[13,29,31,32]$. The removal efficiency and rate are both higher than those observed in this study. Nonetheless, the degradation of naproxen with $\mathrm{Mn}$ (IV) in this study is similar to the results obtained under Mn (IV)-reducing conditions [13], namely $50-60 \%$ naproxen is removed within about 1 month. Metoprolol and propranolol can be degraded under aerobic conditions [13,33] but are resistant to biodegradation under anaerobic conditions [13,31,32,34]. Only under nitrate-reducing conditions, propranolol can be degraded after 10 month. Similarly, the degradation of metoprolol and propranolol are not observed in this experiment. However, our following experiments (Section 3.2(2) and Section 3.3) indicated that metoprolol can be degraded with Mn (IV) $)_{\text {DWTP }}, \mathrm{Fe}(\mathrm{III})_{\text {chem-synthesis, }}$ or Fe(III)-citrate. Similarly, ibuprofen can be readily biodegraded under aerobic conditions, its removal under anaerobic conditions is poor $[10,35]$. Even when the inoculum has been adapted, the removal of ibuprofen under nitrate-reducing conditions are less than $20 \%$ [10]. In our experiments, no ibuprofen degradation is observed. Carbamazepine is considered as a persistent compound under both aerobic and anaerobic conditions [12]. In this experiment, less than $15 \%$ carbamazepine degradation is observed.

(2) Mn(IV) from drinking water treatment plants

$\mathrm{Mn}(\mathrm{IV})_{\mathrm{DWTP}}$, both as granules and ground powder, is tested as whether it is suitable to be used in anaerobic pharmaceutical biodegradation coupled to dissimilatory Mn(IV) reduction. Results show that $\mathrm{Mn}(\mathrm{IV})_{\text {DWTP }}$ granules can remove metoprolol and propranolol via biodegradation. In the first 10 days, the two pharmaceuticals are removed 


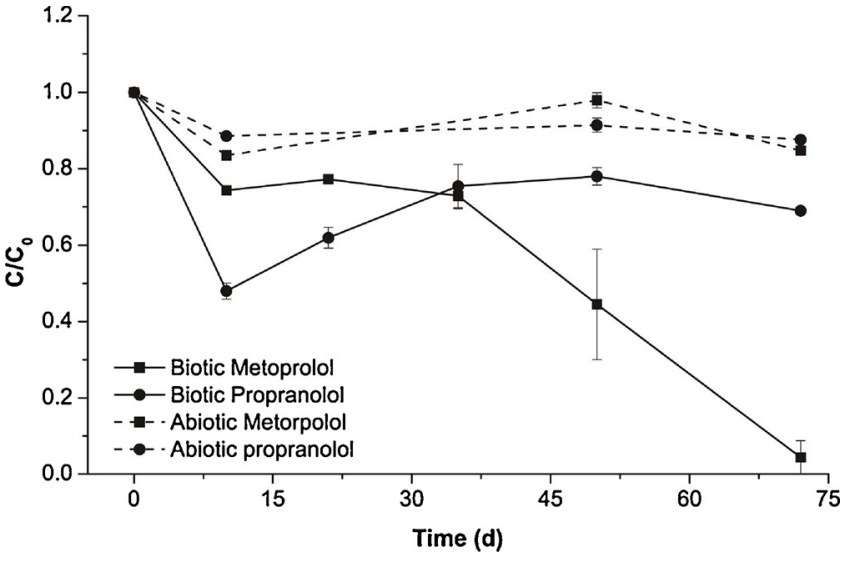

Fig. 3. Biodegradation of metoprolol (O) and propranolol ( $\square$ ) with Mn(IV) oxides from drinking water treatment plants (Mn(IV) $)_{\text {DWTP }}$ ). Experimental conditions: $\left[\mathrm{MnO}_{2}\right]_{0}=15 \mathrm{mM}, \quad[\text { pharmaceutical }]_{0}=10 \mathrm{mg} \mathrm{L}^{-1}, \mathrm{pH}$ 6.5-7.5, $\mathrm{T}=30^{\circ} \mathrm{C}$. Error bars stand for the difference between the duplicate experiments.

with Mn(IV) $)_{\text {DWTP }}$ from the medium in both biotic experiments and abiotic controls (Fig. 3). Thereafter, no removal of metoprolol is observed in biotic experiments between day 10 and day 35, while $72 \%$ is removed in the later 37 days incubation between day 35 and day 72 . The removal of propranolol in biotic experiments is less pronounced, and resulted in a final removal of $31 \%$ after 72 days of incubation. However, the removal of propranolol is $52 \%$ in the first 10 days incubation. During the anaerobic biodegradation with metoprolol and propranolol, $4.9 \mathrm{mM} \mathrm{Mn(IV)} \mathrm{is} \mathrm{reduced} \mathrm{(Table} \mathrm{1).} \mathrm{The} \mathrm{abiotic} \mathrm{controls}$ remained stable after 10 days of incubation, with max. 15\% metoprolol removal, and 9\% propranolol removal. No removal of metoprolol or propranolol is observed in the presence of $\mathrm{Mn}(\mathrm{IV})_{\text {DWTP }}$ powder, $(<5 \%$ removal, data not shown).

The differences between biotic groups and abiotic controls of both propranolol and metoprolol clearly show that the removal of these two pharmaceuticals is via biodegradation. In addition, adsorption is also responsible for the removal of metoprolol and propranolol with Mn

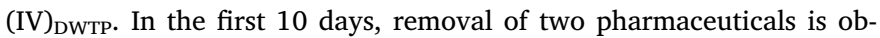
served in both abiotic controls and biotic experiments, but the removal in biotic experiments is higher. These findings show that the biodegradation of pharmaceuticals is the main removal mechanisms, but that adsorption also contributes. After, adsorption reached equilibrium biodegradation becomes the dominant removal process. During this process, metoprolol biodegradation consumes Mn(IV) $)_{\text {DWTP, probably }}$ releasing the propranolol that is adsorbed onto Mn(IV). This might explain the increased concentration of propranolol after 10 days. The $\mathrm{Mn}(\mathrm{IV})$ reduced in this experiments is also higher than expected due to the presence of yeast extract.

As mentioned, degradation of metoprolol and propranolol are negligible under anaerobic conditions [13,31,32,34]. In our experiment, nearly complete removal of metoprolol is obtained within 75 days, which is faster than some studies under aerobic conditions. For example, results show that under aerobic conditions, about $80 \%$ of metoprolol removal is obtained within 120 days [13].

\subsection{Anaerobic biodegradation of metoprolol with $\mathrm{Fe}(\mathrm{III})$}

(1) Chemically synthesized Fe(III) and Fe(III)-citrate

$\mathrm{Fe}(\mathrm{III})$ is hypothesised as a suitable electron acceptor for anaerobic biodegradation of pharmaceuticals, because it has been reported that the bacteria involved can use both Mn(IV) and Fe(III) [17]. We used both insoluble $\mathrm{Fe}(\mathrm{III})_{\text {chem-synthesis }}$ and soluble $\mathrm{Fe}(\mathrm{III})$-citrate to test the anaerobic biodegradation of metoprolol coupled to dissimilatory Fe(III) reduction. Our results show that $\mathrm{Fe}(\mathrm{III})$ is an alternative for

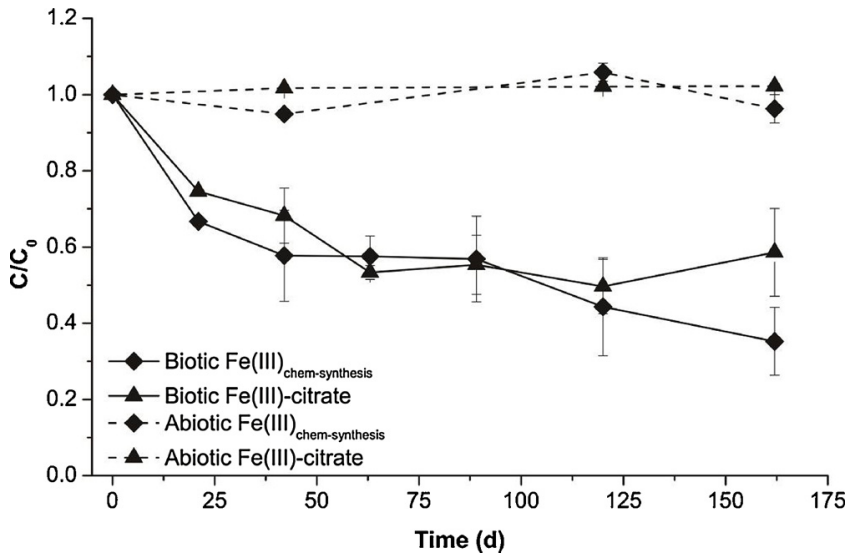

Fig. 4. Biodegradation of metoprolol with chemically produced Fe(III) hydroxides (Fe(III) chem-synthesis $_{\text {) }}(\diamond)$ and $\mathrm{Fe}(\mathrm{III})$-citrate $(\boldsymbol{\Delta})$. Experimental conditions: $[\mathrm{Fe}(\mathrm{III})]_{0}=40 \mathrm{mM}$, [metoprolol $]_{0}=10 \mathrm{mg} \mathrm{L}^{-1}, \mathrm{pH} 6.5-7.5, \mathrm{~T}=30^{\circ} \mathrm{C}$. Error bars stand for the difference between the duplicate experiments.

dissimilatory Mn(IV) reduction, which can be coupled to biodegradation of metoprolol (Fig. 4). Within 162 days, 57\% metoprolol is degraded with $\mathrm{Fe}(\mathrm{III})_{\text {chem-synthesis }}$ and $52 \%$ with $\mathrm{Fe}(\mathrm{III})$-citrate. Based on the theoretical calculation, when $1 \mathrm{mM}$ metoprolol is totally mineralized, $85 \mathrm{mM} \mathrm{Fe(III)} \mathrm{is} \mathrm{reduced} \mathrm{(Text} \mathrm{S2,} \mathrm{Table} \mathrm{S3).}$

Insignificant removal of metoprolol was found in the abiotic controls $(<5 \%)$. This shows that the removal of metoprolol with two different types of $\mathrm{Fe}(\mathrm{III})$ occurs through biodegradation and both can be used by our inoculum that was pre-cultivated with Mn(IV).

In this study, the use of soluble Fe(III)-citrate is expected to result in more removal than insoluble $\mathrm{Fe}(\mathrm{III})_{\text {chem-synthesis, }}$, because the soluble form is more accessible to bacteria. However, our results show no obvious difference between the soluble and insoluble Fe(III). Previous studies reveal that bacteria can directly transfer electrons from organic compounds to insoluble Fe(III) during dissimilatory Fe(III) reduction, without the formation of compounds that serve either as chelator or as electron shuttle [17]. As a result, the solubility of Fe(III) then does not influence its use by bacteria. In addition, Fe(III)-citrate contains an additional carbon source, citrate, which is an easier degradable organic compound than metoprolol. Results show that Fe(III) reduction during metoprolol biodegradation with $\mathrm{Fe}(\mathrm{III})$-citrate is much higher than stoichiometrically needed for the degraded amount of metoprolol (Table 1). Previous studies have reported that some bacteria can use both Mn(IV) and Fe(III) as the electron acceptor [17,27]. Therefore, the inoculum adapted to $\mathrm{Mn}(\mathrm{IV})$ is also active with $\mathrm{Fe}(\mathrm{III})$, indicating that $\mathrm{Mn}(\mathrm{IV})$ and $\mathrm{Fe}(\mathrm{III})$ are exchangeable in application. Based on the theoretical calculation, to remove $52 \%$ metoprolol from $10 \mathrm{mg} \mathrm{L}^{-1}$ requires $1.2 \mathrm{mM} \mathrm{Fe}(\mathrm{III})$. If the citrate is also taken into account and assuming it is totally removed, the Fe(III) required is increased to 721.2 mM. The higher Fe(III) consumption indicates that citrate is also used as electron donor in the reduction of $\mathrm{Fe}(\mathrm{III})$. Citrate will outcompete metoprolol for $\mathrm{Fe}(\mathrm{III})$, leading to less $\mathrm{Fe}(\mathrm{III})$ available for biodegradation of metoprolol.

Even though the metoprolol removal with two Fe(III) is similar, the different intermediates formed in the processes are different (Fig. S2). During the anaerobic metoprolol biodegradation with Fe(III), $1.8 \mathrm{mM}$ $\mathrm{Fe}(\mathrm{III})$ was reduced when $\mathrm{Fe}(\mathrm{III})_{\text {chem-synthesis }}$ is applied, and $8.8 \mathrm{mM} \mathrm{Fe}$ (III) is reduced when Fe(III)-citrate is applied. Since citrate can also be an electron donor, the incomplete biodegradation of citrate could produce intermediates which are expected to be different from that of metoprolol. Furthermore, the presence of citrate as an alternative electron donor could result in co-metabolic conversion of metoprolol, yielding different intermediate products.

(2) Other Fe(III) types

Inoculum obtained from the experiments with $\mathrm{Fe}(\mathrm{III})_{\text {chem-synthesis }}$ 


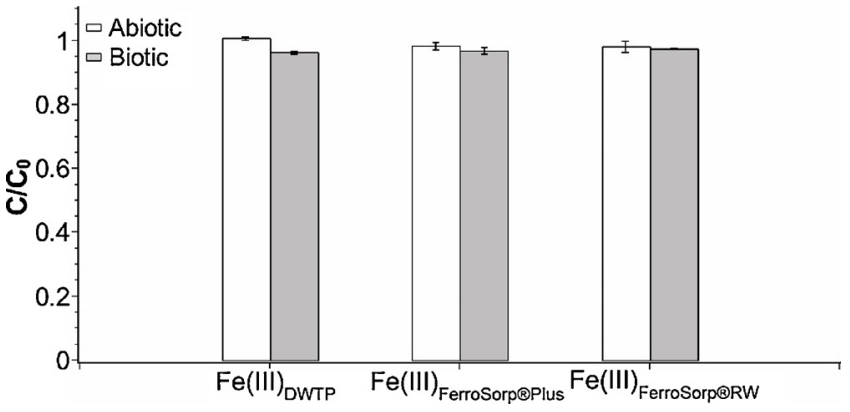

Fig. 5. Degradation of metoprolol with Fe(III) from drinking water treatment

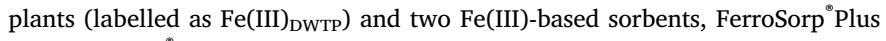

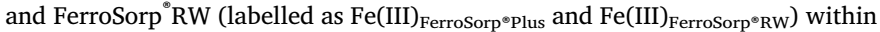
62 days. Experimental conditions: $[\mathrm{Fe}(\mathrm{III})]_{0}=40 \mathrm{mM}$, $[\text { metoprolol }]_{0}=10 \mathrm{mg} \mathrm{L}^{-1}, \mathrm{pH} 6.5-7.5, \mathrm{~T}=30^{\circ} \mathrm{C}$. Error bars stand for the difference between the duplicate experiments.

was tested for its ability to use other insoluble Fe(III) types to remove metoprolol, such as Fe(III) from drinking water treatment plants or commercial $\mathrm{Fe}(\mathrm{III})$ compounds. In this study, Fe(III) $)_{\text {DWTP, }} \mathrm{Fe}$ (III) ${\text { FerroSorp }{ }^{\circledR} \text { Plus }}$ and $\mathrm{Fe}(\mathrm{III})_{\text {FerroSorp }^{\star} \mathrm{RW}}$ are selected because they are cheap, widely available, and theoretically suitable for bacteria in dissimilatory Fe(III) reduction. These Fe(III) compounds can be a good source for electron acceptors in anaerobic biodegradation of pharmaceuticals with $\mathrm{Fe}(\mathrm{III})$. Results show that in both biotic experiments and abiotic controls, the anaerobic metoprolol degradation is less than $10 \%$ after 62 days incubation, indicating no significant removal of metoprolol (Fig. 5).

The insignificant removal of metoprolol with these three types of $\mathrm{Fe}$ (III) might be due to their semi-crystalline form instead of having an amorphous nature. Previous studies show that reduction rate using crystalline $\mathrm{Fe}(\mathrm{III})$ in dissimilatory $\mathrm{Fe}(\mathrm{III})$ reduction is much slower compared to amorphous Fe(III) [17]. In addition, the microbial inoculum was cultivated with amorphous Fe(III) for a long period (over 200d) before transfer. When semi-crystalline Fe(III) was used instead of amorphous Fe(III), this inoculum may need a longer time before the degradation of metoprolol is initiated. As a result, no anaerobic metoprolol degradation via dissimilatory Fe(III) reduction is observed with these widely available Fe (III) forms.

\section{Conclusion}

Our study shows that anaerobic biodegradation coupled to dissimilatory $\mathrm{Mn}(\mathrm{IV})$ or $\mathrm{Fe}(\mathrm{III})$ reduction is promising to remove pharmaceuticals. Based on these results, the following conclusions can be reached:

(1) Anaerobic biodegradation with Mn(IV) can be used to remove pharmaceuticals including caffeine and naproxen, and the resistant pharmaceutical, metoprolol.

(2) Fe(III) can be used as an alternative electron acceptor in anaerobic biodegradation of metoprolol with Mn(IV).

(3) Different types of $\mathrm{Mn}(\mathrm{IV})$ or Fe(III) can be used in the anaerobic biodegradation of pharmaceuticals. The removal efficiency may be related to the morphologies of these Mn(IV) or Fe(III) compounds.

(4) During the degradation process, the presence of yeast extract, citrate and other (metal complexing) organic components will compete with pharmaceuticals for iron or manganese reduction, and may thereby inhibit the dissimilatory removal of pharmaceuticals.

In comparison to previous studies under anaerobic conditions using different electron acceptors, biodegradation of pharmaceuticals with $\mathrm{Mn}(\mathrm{IV})$ or $\mathrm{Fe}(\mathrm{III})$ is more efficient for the removal of persistent compounds like metoprolol. In addition, the Mn(IV) or Fe(III) used in this process is widely available, easy to acquire and cheap, and easy to recycled via low-energy process. It is a promising process in the future wastewater treatment removing pharmaceuticals.

In summary, anaerobic biodegradation coupled to dissimilatory Mn (IV) or Fe(III) reduction can be used for pharmaceutical removal. This pharmaceutical removal process is effective with different types of Mn (IV) and Fe(III), including some widely available $\mathrm{Mn}$ (IV) and Fe(III) forms such as $\mathrm{Mn}$ (IV) present in sludge waste originating from drinking water treatment plants. Care should be taken of competing for organic substrates during removal of pharmaceuticals from wastewater treatment plant effluents. Further investigation based on the fundamental insight into this more sustainable pharmaceutical removal technology in wastewater treatment processes provided by this study is required. In addition, our study also contribute to understanding biotransformation of pharmaceuticals in the environment.

\section{Acknowledgements}

The study is finical supported by China Scholarship Council (File No. 201308610161) and Wageningen University \& Research. The authors appreciate the help from Laura Piai (WUR) and Peter van der Maas (WLN) for the experimental materials and additional information. The authors also appreciate the help from Hans Beijleveld, Livio Carlucci, Ilse Gerrits, Jean Slangen, and Vinnie de Wilde for assistance in analysis, and Marijn van Son for the work with Mn(IV) oxides from drinking water treatment plants.

\section{Appendix A. Supplementary data}

Supplementary material related to this article can be found, in the online version, at doi:https://doi.org/10.1016/j.jhazmat.2018.04.078.

\section{References}

[1] E. Archer, B. Petrie, B. Kasprzyk-Hordern, G.M. Wolfaardt, The fate of pharmaceuticals and personal care products (PPCPs), endocrine disrupting contaminants (EDCs), metabolites and illicit drugs in a WWTW and environmental waters, Chemosphere 174 (2017) 437-446.

[2] Z. Li, A. Sobek, M. Radke, Fate of pharmaceuticals and their transformation products in four small European rivers receiving treated wastewater, Environ. Sci. Technol. 50 (2016) 5614-5621.

[3] D.B. Huggett, B.W. Brooks, B. Peterson, C.M. Foran, D. Schlenk, Toxicity of select beta adrenergic receptor-blocking pharmaceuticals (B-blockers) on aquatic organisms, Arch. Environ. Contam. Toxicol. 43 (2002) 229-235.

[4] J.P. Besse, J. Garric, Human pharmaceuticals in surface waters: implementation of a prioritization methodology and application to the French situation, Toxicol. Lett. 176 (2008) 104-123.

[5] Eurpoean Union, Directive 2013/39/EU of the European Parliament and of the Council, (2013) (Accessed 6 March 2017), http://eur-lex.europa.eu/legal-content/ $\mathrm{EN} / \mathrm{TXT} / \mathrm{PDF} /$ ?uri $=$ CELEX:32013L0039\&from $=$ EN .

[6] J. Wang, S. Wang, Removal of pharmaceuticals and personal care products (PPCPs) from wastewater: a review, J. Environ. Manage. 182 (2016) 620-640.

[7] Y.J. He, N.B. Sutton, H.H.H. Rijnaarts, A.A.M. Langenhoff, Degradation of pharmaceuticals in wastewater using immobilized $\mathrm{TiO}_{2}$ photocatalysis under simulated solar irradiation, Appl. Catal. B-Environ. 182 (2016) 132-141.

[8] Y. Ye, Y. Feng, H. Bruning, D. Yntema, H.H.M. Rijnaarts, Photocatalytic degradation of metoprolol by $\mathrm{TiO}_{2}$ nanotube arrays and UV-LED: effects of catalyst properties, operational parameters, commonly present water constituents, and photo-induced reactive species, Appl. Catal. B-Environ. 220 (2018) 171-181.

[9] H. Olvera-Vargas, N. Oturan, E. Brillas, D. Buisson, G. Esposito, M.A. Oturan, Electrochemical advanced oxidation for cold incineration of the pharmaceutical ranitidine: mineralization pathway and toxicity evolution, Chemosphere 117 (2014) 644-651.

[10] A. Langenhoff, N. Inderfurth, T. Veuskens, G. Schraa, M. Blokland, K. KujawaRoeleveld, H. Rijnaarts, Microbial removal of the pharmaceutical compounds ibuprofen and diclofenac from wastewater, Biomed. Res. Int. 9 (2013), https://doi.org/ $10.1155 / 2013 / 325806$.

[11] A.K. Ghattas, F. Fischer, A. Wick, T.A. Ternes, Anaerobic biodegradation of (emerging) organic contaminants in the aquatic environment, Water Res. 116 (2017) 268-295.

[12] E.G. Garrido-Ramirez, M.V. Sivaiah, J. Barrault, S. Valange, B.K.G. Theng, M.S. Ureta-Zanartu, M.D. Mora, Catalytic wet peroxide oxidation of phenol over iron or copper oxide-supported allophane clay materials: influence of catalyst $\mathrm{SiO}_{2}$ $\mathrm{Al}_{2} \mathrm{O}_{3}$ ratio, Microporous Mesoporous Mater. 162 (2012) 189-198.

[13] N. Schmidt, D. Page, A. Tiehm, Biodegradation of pharmaceuticals and endocrine 
disruptors with oxygen, nitrate, manganese (IV), iron (III) and sulfate as electron acceptors, J. Contam. Hydrol. 203 (2017) 62-69.

[14] M. Barbieri, J. Carrera, X. Sanchez-Vila, C. Ayora, J. Cama, M. Kock-Schulmeyer, M.L. de Alda, D. Barcelo, J.T. Brunet, M.H. Garcia, Microcosm experiments to control anaerobic redox conditions when studying the fate of organic micropollutants in aquifer material, J. Contam. Hydrol. 126 (2011) 330-345.

[15] V.G. Samaras, A.S. Stasinakis, N.S. Thomaidis, D. Mamais, T.D. Lekkas, Fate of selected emerging micropollutants during mesophilic, thermophilic and temperature co-phased anaerobic digestion of sewage sludge, Bioresour. Technol. 162 (2014) 365-372.

[16] W. Park, Y.K. Nam, M.J. Lee, T.H. Kim, Anaerobic ammonia-oxidation coupled with $\mathrm{Fe}^{3+}$ reduction by an anaerobic culture from a piggery wastewater acclimated to $\mathrm{NH}^{4+} / \mathrm{Fe}^{3+}$ medium, Biotechnol. Bioproc. Eng. 14 (2009) 680-685.

[17] D. Lovley, Dissimilatory Fe(III)- and Mn(IV)-reducing prokaryotes, in: E. Rosenberg, E.F. DeLong, S. Lory, E. Stackebrandt, F. Thompson (Eds.), The Prokaryotes: Prokaryotic Physiology and Biochemistry, Springer, Berlin, Heidelberg, 2013, pp. 287-308.

[18] A.A.M. Langenhoff, A.J.B. Zehnder, G. Schraa, Behaviour of toluene, benzene and naphthalene under anaerobic conditions in sediment columns, Biodegradation 7 (1996) 267-274.

[19] G.K. Khadse, P.M. Patni, P.K. Labhasetwar, Removal of iron and manganese from drinking water supply, Sustain. Water Resour. Manage. 1 (2015) 157-165.

[20] D. Ociński, I. Jacukowicz-Sobala, P. Mazur, J. Raczyk, E. Kociołek-Balawejder, Water treatment residuals containing iron and manganese oxides for arsenic removal from water-characterization of physicochemical properties and adsorption studies, Chem. Eng. J. 294 (2016) 210-221.

[21] W. Liu, N.B. Sutton, H.H.M. Rijnaarts, A.A.M. Langenhoff, Anoxic conditions are beneficial for abiotic diclofenac removal from water with manganese oxide $\left(\mathrm{MnO}_{2}\right)$, Environ. Sci. Pollut. Res. (2018), https://doi.org/10.1007/s11356-018-1569-2.

[22] R. Bos, Spoelwaterbehandeling in Emmen, H2O, 29 (1996) 624-628.

[23] D.R. Lovley, E.J.P. Phillips, Organic matter mineralization with reduction of ferric iron in anaerobic sediments, Appl. Environ. Microb. 51 (1986) 683-689.

[24] Y. He, S. Nurul, H. Schmitt, N.B. Sutton, T.A.J. Murk, M.H. Blokland,

H.H.M. Rijnaarts, A.A.M. Langenhoff, Evaluation of attenuation of pharmaceuticals, toxic potency, and antibiotic resistance genes in constructed wetlands treating wastewater effluents, Sci. Total Environ. 631-632 (2018) 1572-1581.

[25] L.-J. Ding, X.-L. An, S. Li, G.-L. Zhang, Y.-G. Zhu, Nitrogen loss through anaerobic ammonium oxidation coupled to iron reduction from paddy soils in a chronosequence, Environ. Sci. Technol. 48 (2014) 10641-10647.

[26] Y. He, J. Xu, Y. Zhang, C. Guo, L. Li, Y. Wang, Oxidative transformation of carbamazepine by manganese oxides, Environ. Sci. Pollut. Res. 19 (2012) 4206-4213.

[27] D.R. Lovley, D.E. Holmes, K.P. Nevin, Dissimilatory Fe(III) and Mn(IV) reduction, Adv. Microb. Physiol. 49 (2004) 219-286.

[28] J. Maszkowska, S. Stolte, J. Kumirska, P. Lukaszewicz, K. Mioduszewska, A. Puckowski, M. Caban, M. Wagil, P. Stepnowski, A. Bialk-Bielinska, Beta-blockers in the environment: part I. Mobility and hydrolysis study, Sci. Total Environ. 493 (2014) 1112-1121.

[29] S. Froehner, W. Piccioni, K.S. Machado, M.M. Aisse, Removal capacity of caffeine, hormones, and bisphenol by aerobic and anaerobic sewage treatment, Water Air Soil Pollut. 216 (2011) 463-471.

[30] A.S. Stasinakis, Review on the fate of emerging contaminants during sludge anaerobic digestion, Bioresour. Technol. 121 (2012) 432-440.

[31] Y. He, N.B. Sutton, H.H.M. Rijnaarts, A.A.M. Langenhoff, Pharmaceutical biodegradation under three anaerobic redox conditions evaluated by chemical and toxicological analyses, Sci. Total Environ. 618 (2018) 658-664.

[32] A. de Wilt, Y. He, N. Sutton, A. Langenhoff, H. Rijnaarts, Sorption and biodegradation of six pharmaceutically active compounds under four different redox conditions, Chemosphere 193 (2018) 811-819.

[33] S. Sathyamoorthy, K. Chandran, C.A. Ramsburg, Biodegradation and cometabolic modeling of selected beta blockers during ammonia oxidation, Environ. Sci. Technol. 47 (2013) 12835-12843.

[34] M. Barbieri, T. Licha, K. Nödler, J. Carrera, C. Ayora, X. Sanchez-Vila, Fate of $\beta$ blockers in aquifer material under nitrate reducing conditions: batch experiments, Chemosphere 89 (2012) 1272-1277.

[35] S.E. Musson, P. Campo, T. Tolaymat, M. Suidan, T.G. Townsend, Assessment of the anaerobic degradation of six active pharmaceutical ingredients, Sci. Total Environ. 408 (2010) 2068-2074. 